\title{
Highly Responsive UV Light Sensors Using Mg-Doped ZnO Nanoparticles
}

\author{
Mirza Shirjeel Alam, ${ }^{1}$ Umair Manzoor, ${ }^{1,2}$ Mohammad Mujahid, ${ }^{3}$ and Arshad S. Bhatti ${ }^{1}$ \\ ${ }^{1}$ Center for Micro and Nano Devices (CMND), Department of Physics, COMSATS Institute of Information Technology, \\ Islamabad 44000, Pakistan \\ ${ }^{2}$ Alamoudi Water Research Chair, King Saud University, P.O. Box 2460, Riyadh 11451, Saudi Arabia \\ ${ }^{3}$ School of Chemical \& Materials Engineering (SCME), National University of Sciences \& Technology (NUST), Sector H-12, \\ Islamabad 44000, Pakistan \\ Correspondence should be addressed to Umair Manzoor; umanzoor@ksu.edu.sa
}

Received 30 December 2015; Revised 4 February 2016; Accepted 28 February 2016

Academic Editor: Christos Riziotis

Copyright (C) 2016 Mirza Shirjeel Alam et al. This is an open access article distributed under the Creative Commons Attribution License, which permits unrestricted use, distribution, and reproduction in any medium, provided the original work is properly cited.

\begin{abstract}
Different concentrations of $\mathrm{Mg}$-doped $\mathrm{ZnO}$ nanoparticles (NPs) were synthesized by coprecipitation technique at $60^{\circ} \mathrm{C}$. XRD data are used to study phase purity and crystal structure in different doping concentrations. The results indicated that increasing the doping from 0 7.5 wt.\% caused a subsequent increase in FWHM in XRD and an associated systematic shift towards higher wavelength in the optical properties. Finally, the sensing of UV light is tested by observing the response of nanoparticles by exposing them to UV light and measuring the resistance in presence and absence of UV light.
\end{abstract}

\section{Introduction}

Oxides are now a smart choice and basis of advanced and multifunctional devices [1]. Device fabrication and synthesis using oxides semiconductor have become more important recently because the physical properties are size dependent and can be tuned. Among oxide semiconductor family, $\mathrm{ZnO}$ is a wide bandgap material (3.37 eV at room temperature) with large exciton binding energy $(60 \mathrm{meV})$ and strong photocatalytic, optical, and piezoelectric properties. They are used in solar cells, photocatalysis and antibacterial active material [2], gas sensors [3], and UV (Ultraviolet) light emitting/detecting devices [4]. ZnO is also an integral part of green luminescence phosphor in fluorescent devices [5].

UV sensors are widely used in different applications, such as pollution monitoring, flame sensing, early missile plume detection, and other advanced military applications [6]. Different types of Si-based photodetectors are already available in the market and are very sensitive with low noise and quick response [5]. However, applications are limited as some need ultrahigh vacuum or high voltage supply (i.e., in photomultipliers) or time dependent degradation and lower efficiency [7]. To overcome these disadvantages, new materials such as diamond, $\mathrm{SiC}$, oxide semiconductors, and nitrides are a focus of research because of their intrinsic visible-blindness. Also, chemical and thermal stability at operating conditions are far better than the conventional materials. Moreover, their optical properties are slightly temperature dependent $[8,9]$. One of the possible materials which fulfills most of these requirements is $\mathrm{ZnO}$. Therefore, it has been studied extensively recently to further explore its potential applications in electronics and optoelectronics [10]. Furthermore, different doping in $\mathrm{ZnO}$ (i.e., $\mathrm{Mg}$ ) can adjust bandgap to make UV photodetectors in different UV regime $[11,12]$. Despite a great deal of research on $\mathrm{ZnO}$ UV detector, most of the research concentrated on the improvements of the micromask electrodes, in order to enhance the performance of the $\mathrm{ZnO}$ photoconductive detectors [11]. $\mathrm{ZnO}$ sensing mechanism can be linked with surface reactions. Hence, grain size, defects, and oxygen adsorption are important parameters for controlling sensing response [3].

In the present study, systematic $\mathrm{Mg}$ doping (0 7.5 wt.\%) in $\mathrm{ZnO}$ NPs was achieved and is analysed by XRD, FTIR, and 
TABLE 1: Experimental details and chemical quantities used for the synthesis.

\begin{tabular}{ccccccl}
\hline$\#$ & $\%$ age doping & $\mathrm{Zn}\left(\mathrm{CH}_{3} \mathrm{COO}\right)_{2}(\mathrm{~g})$ & $\mathrm{Mg}\left(\mathrm{CH}_{3} \mathrm{COO}\right)_{2}(\mathrm{~g})$ & $\mathrm{KOH}(\mathrm{g})$ & Ethanol $(\mathrm{mL})$ & Other constants (same for all experiments) \\
\hline 1 & $0 \%$ & 1.004 & - & 0.990 & 80 & Temperature: $60^{\circ} \mathrm{C}$ \\
2 & $2.5 \%$ & 1.009 & 0.020 & 1.008 & 80 & Constant stirring: 2.5 hours \\
3 & $5.0 \%$ & 1.007 & 0.041 & 0.960 & 80 & Centrifuged to separate $\mathrm{ZnO} \mathrm{NPs}$ \\
4 & $7.5 \%$ & 1.003 & 0.078 & 0.962 & 80 & Repeatedly washed with distilled water and \\
\hline
\end{tabular}

UV-Vis spectroscopy. Optical properties were tuned by $\mathrm{Mg}$ doping. UV sensing properties are also demonstrated. The main focus of the study was the fast response time of $\mathrm{Mg}$ doped $\mathrm{ZnO}$ NPs as active sensor material.

\section{Experimental Section}

Zinc acetate dihydrate $\left(\mathrm{Zn}\left(\mathrm{CH}_{3} \mathrm{COO}\right)_{2}\right.$, Sigma-Aldrich $)$ and $1 \mathrm{~mL}$ of water (distilled) were put into a flask containing $80 \mathrm{~mL}$ methanol. They were mixed at $60^{\circ} \mathrm{C}$. In a second beaker, potassium hydroxide (KOH, Sigma-Aldrich) was dissolved in $23 \mathrm{~mL}$ of methanol. The solution was then slowly added into the flasks containing zinc acetate. This mixture was then stirred for 2.5 hours. The transparent solution became opaque because of slow addition of $\mathrm{KOH}$ which, again, slowly transformed into a clear solution. $\mathrm{ZnO}$ powder was separated from the solvent by centrifuge and repeatedly washed in distilled water and ethanol. The powder was dried in convection oven at $60^{\circ} \mathrm{C}$. For doping, magnesium acetate dihydrate $\left(\mathrm{Mg}\left(\mathrm{CH}_{3} \mathrm{COO}\right)_{2}\right.$ Sigma-Aldrich) was added in appropriate quantities. The experimental details and quantities are shown in Table 1.

The morphology was determined using transmission electron microscope (TEM, JEOL). The phase analysis was done using X-ray diffraction technique (JDX-11, Japan). Diffuse reflectance spectroscopy (DRS) of NPs was done by using a Lamda-950 Perkin-Elmer. Thick film sensors were made by doctor blading (same area and thickness for all sensors) and resistance was measured using multimeter (Keithly 2000 multimeter).

\section{Results and Discussion}

Figure 1 illustrates XRD spectrum of different NPs prepared by the coprecipitation method. All major diffraction peaks can be assigned to diffraction from different $\mathrm{ZnO}$ planes, respectively (JCPDS card \# 780-0075). There is a weak peak at about $27^{\circ}$ in $5 \% \mathrm{Mg}$-doped sample, which can be due to $\mathrm{Zn}\left(\mathrm{CH}_{3} \mathrm{COO}\right)_{2}$ as a result of unwanted residue left in the sample [14]. This revealed that the resultant NPs were phasepure $\mathrm{ZnO}$ (no $\mathrm{MgO}$ peaks) with a hexagonal structure. $\mathrm{MgO}$ has rock-salt structure and $\mathrm{ZnO}$ has hexagonal structure. Therefore, phase separation can occur at higher concentrations. The XRD spectra clearly suggest that there is no phase separation. $\mathrm{Zn}$ and $\mathrm{Mg}$ ions have similar ionic radii (0.60 and $0.57 \AA$ ) and it is expected that $\mathrm{Mg}$ ions are substituted for $\mathrm{Zn}$. The systematic peak shift and broader FWHM with consistent increase in $\mathrm{Mg}$ doping is are indication of doping, suggesting a higher defect concentration and decreased quality of crystal

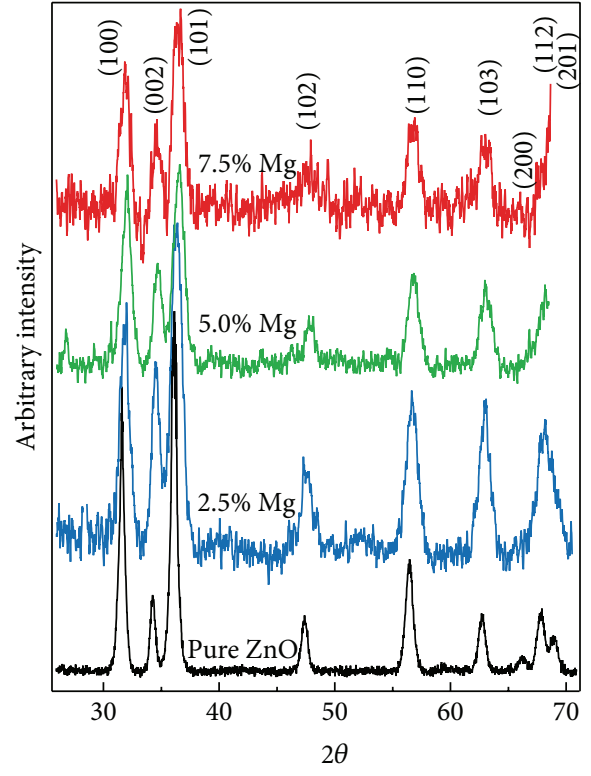

FIGURE 1: XRD spectra of different levels of $\mathrm{Mg}$ doping in $\mathrm{ZnO}$ NPs. The results clearly show that all the major peaks correspond to $\mathrm{ZnO}$. There is a systematic broadening of FWHM with an increase in doping concentration.

with increase in $\mathrm{Mg}$ doping concentration. Also, there is a clear systematic (101) peak (highest intensity) shift towards higher 2 theta value. This again is another indication of change in " $d$ " spacing with increase in the doping concentration. Figure S1 (at Supplementary Material available online at http://dx.doi.org/10.1155/2016/8296936) shows a TEM image of pure $\mathrm{ZnO}$ NPs and clearly suggests that the average particle size is less than $10 \mathrm{~nm}$. Also, there are 2 minor peaks ((200) and (201)) which disappear after doping. One of the possible reasons can be that these peaks shift because of the Mg-induced strain and merge into the broader (112) peak. This peak broadening can be clearly observed if XRD spectra of pure $\mathrm{ZnO}$ and $2.5 \% \mathrm{Mg}$ samples are compared. Also, the morphology is dependent on doping and previous researchers suggested that grain size increases with increase in doping concentration.

Figure 2 represents the FTIR results in the range of $4000 \mathrm{~cm}^{-1}$ to $500 \mathrm{~cm}^{-1} .3550 \mathrm{~cm}^{-1}$ to $3250 \mathrm{~cm}^{-1}$ band is typically the stretching vibration mode of $\mathrm{OH}^{-}$group. Also, $1650 \mathrm{~cm}^{-1}$ band is the $\mathrm{OH}^{-}$fundamental stretching mode. These bands are very typical signals of $\mathrm{H}_{2} \mathrm{O}$ present on the sample surface. $\mathrm{Zn}-\mathrm{O}$ stretching mode is located at $560 \mathrm{~cm}^{-1}$ 


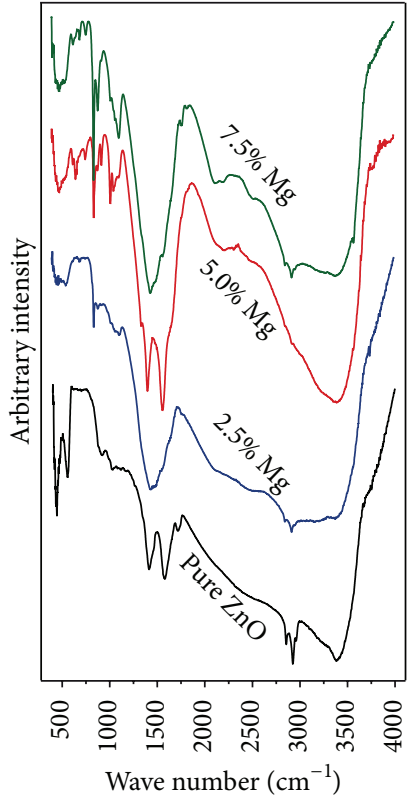

FIGURE 2: FTIR results of different levels of Mg doping in ZnO NPs. A clear change of $\mathrm{ZnO}$ stretching modes with increase in $\mathrm{Mg}$ doping (around $500 \mathrm{~cm}^{-1}$ ) suggests that $\mathrm{Zn}$ ions are replaced by $\mathrm{Mg}$ ions.

to $600 \mathrm{~cm}^{-1}$ [15]. There is a slight systematic peak shift of $\mathrm{Zn}$ $\mathrm{O}$ band which can be an indirect evidence of increasing $\mathrm{Mg}$ content in the lattice. $\mathrm{Mg}-\mathrm{O}$ stretching vibrations can also be clearly observed in the region of $1400 \mathrm{~cm}^{-1}$ to $1450 \mathrm{~cm}^{-1}$. FTIR results give a clear indication that $\mathrm{Mg}$ was successfully doped in $\mathrm{ZnO}$ lattice $[15,16]$.

Bandgap of $\mathrm{ZnO}$ NPs can be effectively tuned by doping $\mathrm{Mg}^{2+}$. The bandgap of $\mathrm{ZnO}$ and $\mathrm{MgO}$ is $3.37 \mathrm{eV}$ and $7.7 \mathrm{eV}$, respectively, and it can be increased by $\mathrm{Mg}$ doping [12]. The UV-visible spectroscopy results are shown in Figure 3. The bandgap of all the samples can be estimated by converting wave length into the energy using the following equation:

$$
E=h c \backslash \lambda,
$$

where " $E$ " is energy, " $h$ " is Plank's constant, "c" is velocity of light, and " $\lambda$ " is the wave length. A systematic blue shift in the main UV peak can be clearly observed with the increase in the $\mathrm{Mg}$ doping and the bandgap ranges from $3.24 \mathrm{eV}$ for pure $\mathrm{ZnO}$ to $3.33 \mathrm{eV}$ for $7.5 \% \mathrm{Mg}$ samples. Our results are in accordance with the previous studies and clearly show that bandgap can be tuned by carefully controlling Mg doping [17, 18]. One of the possible explanations of this blue shift is the Burstein-Moss effect. Fermi level of $\mathrm{n}$ type $\mathrm{ZnO}$ is inside the conduction band. With Mg doping, the conduction bands are filled. This in turn shifts the absorption edge to the higher energy [19].

Photoconductive response time is important for a UV sensor. Electron-hole pairs are generated on UV exposure. These holes are then combined with trapped oxygen ions, commonly known as surface electron-hole recombination. This effect is shown in [20]

$$
\mathrm{h}^{+}+\mathrm{O}_{2}^{-}(\mathrm{ad}) \longrightarrow \mathrm{O}_{2} \text { (gas) }
$$

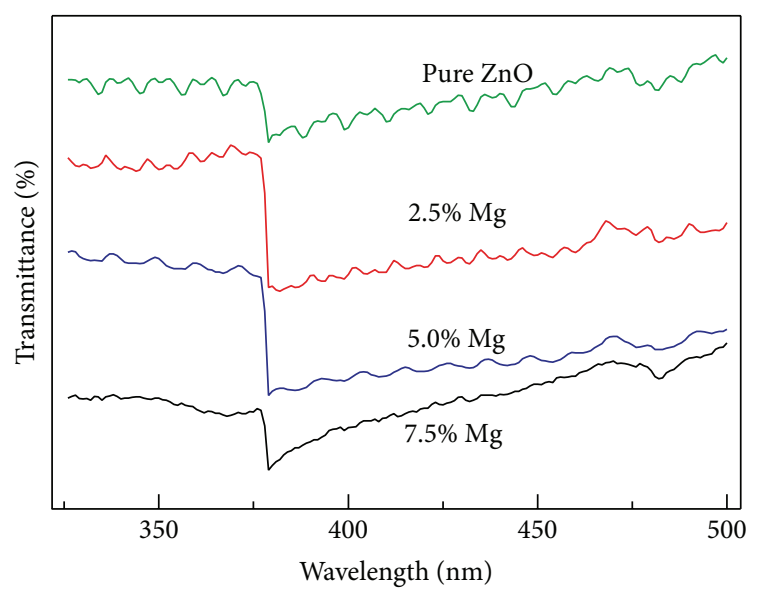

FIGURE 3: UV-Vis spectroscopy of samples with pure and different concentrations of $\mathrm{Mg}$-doped $\mathrm{ZnO}$. The results give a clear indication of direct band emission, in UV region, for all the samples. There is also a systematic shift towards higher wavelength for UV emission. Minor peaks around $475 \mathrm{~nm}$ can be the defect related deep-level emission peaks [13].

Unpaired electrons are freely available and enhance the photocurrent. Figure 4 is the sensing results of Mg-doped $\mathrm{ZnO}$ NPs done at room temperature. The On-Off switch time was very small (in seconds) and one of the main focuses of this experiment was to investigate the response time and change in resistance with $\mathrm{Mg}$ doping. The sensitivity (ratio of resistance in the dark and in the presence of UV light) is $1.060,1.062,1.088$, and 1.054 for $0 \%, 2.5 \%, 5.0 \%$, and $7.5 \%$, respectively. The enhanced response of Mg-doped $\mathrm{ZnO}$ NPs can be attributed to unpaired electrons added to the photocurrent $[21,22]$. In $\mathrm{ZnO}$, oxygen vacancies act as electron donors. Surface defects and charged species increase after the Mg doping, thus more reaction and surface recombination results in faster response time. Also, NPs are a good choice for obtaining fast response of the devices due to an enhanced surface to volume ratio [23]. However, the decrease in sensitivity after $7.5 \% \mathrm{Mg}$ can be attributed to severe damage in the crystal lattice. Previous researchers have also suggested that the $\mathrm{Mg}$-doped $\mathrm{ZnO}$ (and $\mathrm{Zn}_{1-x} \mathrm{Mg}_{x} \mathrm{O}$ ) having potential photodetectors with different detective wavelengths have strong potential for being the sensor active material. However, there is a wide miscibility gap and large lattice mismatch in the $\mathrm{ZnO}-\mathrm{MgO}$ binary system. This is mainly because of the difference in crystal structure. Therefore, defect density increases and crystal quality is low. Also phase segregation can occur. This has become the major issue for synthesis. Also, finding new materials with faster adsorption and disadsorption characteristics is the main issue which is attracting the attention of researchers in this field [24-28]. It was also suggested that, usually with doping, the bandgap is shifted to the lower energy region, which enhances the absorption spectrum of doped ZnO NPs [29]. These are the main issues which are attracting the attention of researchers in this field. 


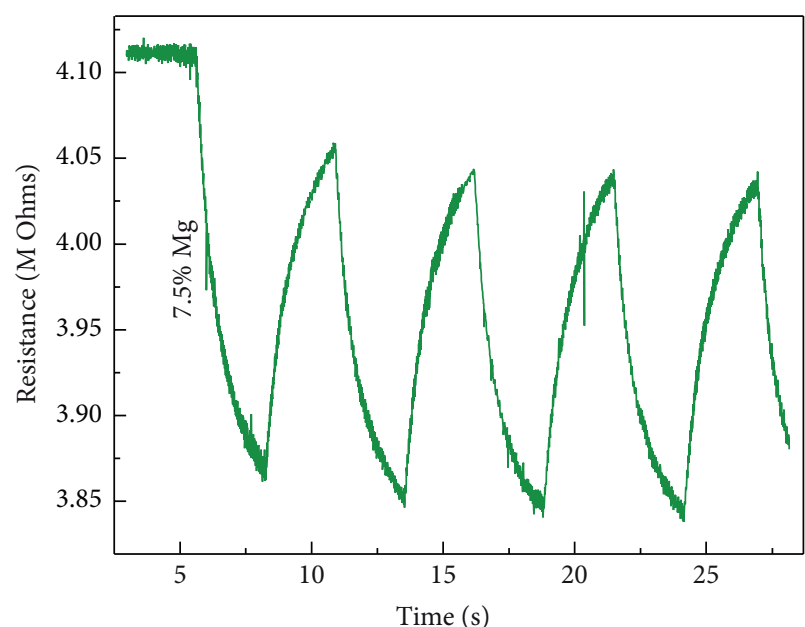

(a)

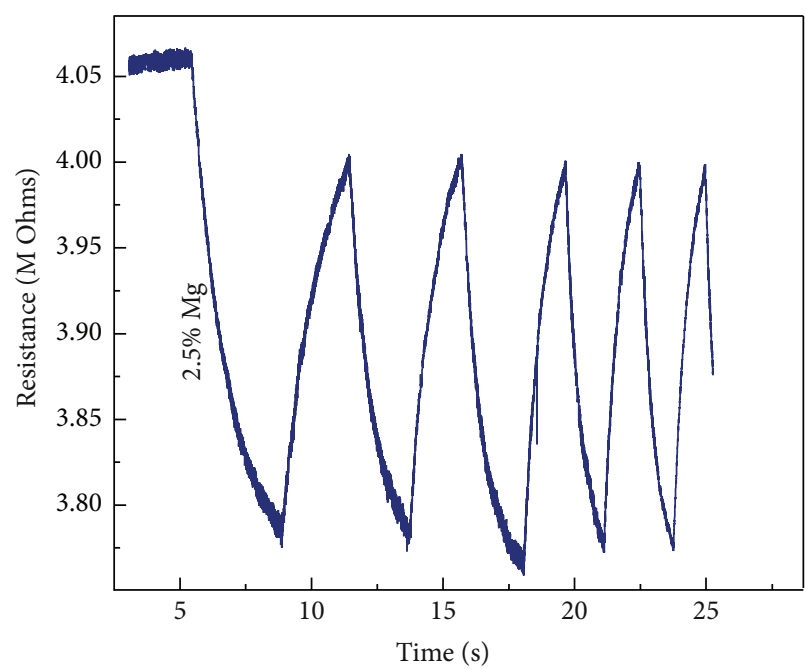

(c)

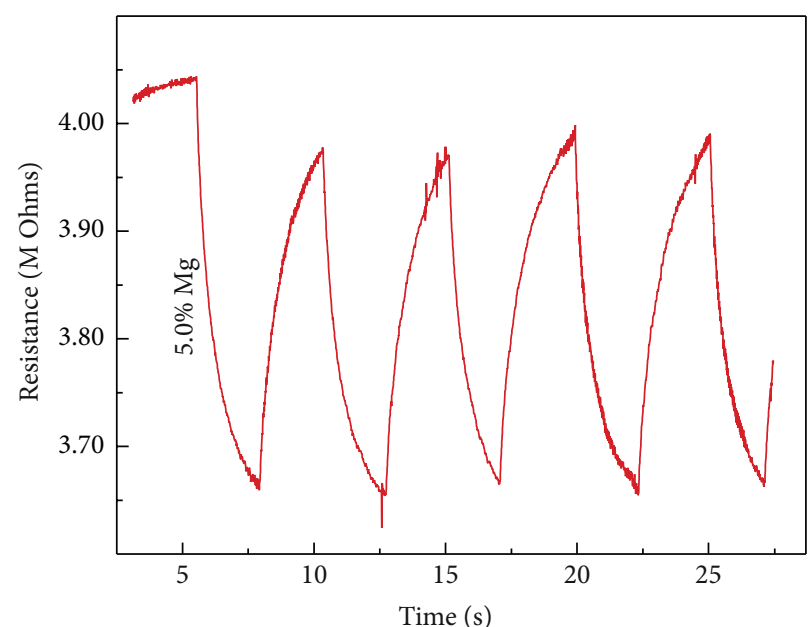

(b)

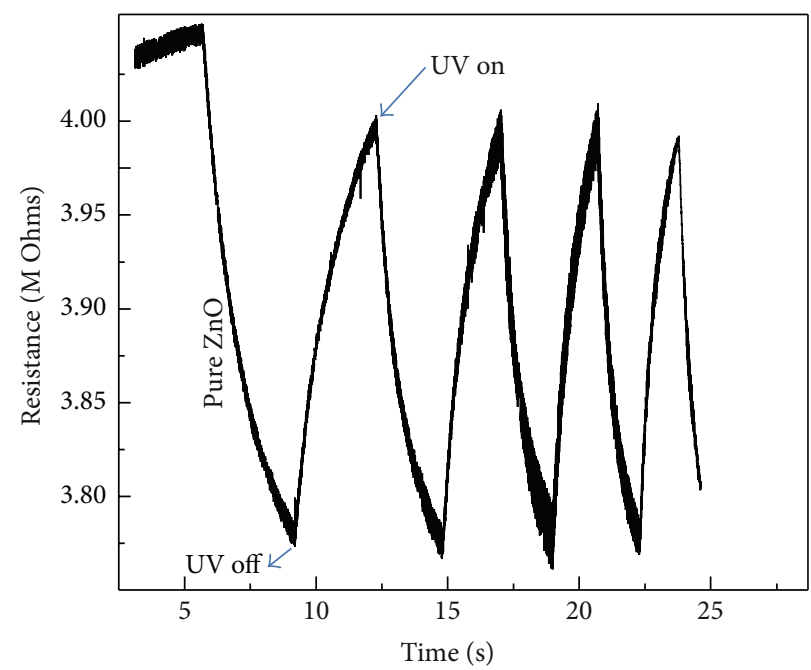

(d)

Figure 4: Room temperature UV sensor results of different samples with Mg doping (a) 7.5\% (b), 5.0\%, (c) 2.5\%, and (d) pure ZnO. The results clearly suggest good sensitivity for all the doped and undoped samples.

$\mathrm{XRD}$, UV-Vis spectroscopy, and optical sensor results are in perfect agreement with each other. There is a systematic peak shift in XRD and UV-Vis results with increase in $\mathrm{Mg}$ doping. XRD peak shift also indicates changes in "d spacing." The UV sensing properties of Mg-doped ZnO NPs show fast switching behavior due to adsorbed oxygen.

\section{Conclusions}

Pure and Mg-doped ZnO NPs were prepared by coprecipitation method at $60^{\circ} \mathrm{C}$. XRD spectra show a regular peak shift towards higher angle with a wider FWHM. FTIR results give a clear indication of the presence of $\mathrm{Mg}$ atoms in the lattice by showing $\mathrm{Zn}-\mathrm{O}$ band shift towards the high energy and also the appearance of $\mathrm{Mg}-\mathrm{O}$ vibration peak. One of the motives of $\mathrm{Mg}$ doping is to tune the optical properties of $\mathrm{ZnO}$ NPs. The bandgap of NPs was directly related to the concentration of $\mathrm{Mg}$ atoms in particles. The sensing results showed very fast response towards UV light for all the samples.

\section{Competing Interests}

The authors declare that there is no conflict of interests regarding the publication of this paper.

\section{Authors' Contributions}

Mirza Shirjeel Alam, Umair Manzoor, Mohammad Mujahid, and Arshad S. Bhatti contributed equally to this work.

\section{Acknowledgments}

This project was funded by the National Plan for Science, Technology and Innovation (MAARIFAH), King Abdulaziz 
City for Science and Technology, Kingdom of Saudi Arabia, Award no. 2623.

\section{References}

[1] Z. R. Dai, Z. W. Pan, and Z. L. Wang, "Novel nanostructures of functional oxides synthesized by thermal evaporation," Advanced Functional Materials, vol. 13, no. 1, pp. 9-24, 2003.

[2] K. Rekha, M. Nirmala, M. G. Nair, and A. Anukaliani, "Structural, optical, photocatalytic and antibacterial activity of zinc oxide and manganese doped zinc oxide nanoparticles," Physica B: Condensed Matter, vol. 405, no. 15, pp. 3180-3185, 2010.

[3] M. Amin, U. Manzoor, M. Islam, A. S. Bhatti, and N. A. Shah, "Synthesis of $\mathrm{ZnO}$ nanostructures for low temperature $\mathrm{CO}$ and UV sensing," Sensors, vol. 12, no. 10, pp. 13842-13851, 2012.

[4] L. Peng, L. Hu, and X. Fang, "Low-dimensional nanostructure ultraviolet photodetectors," Advanced Materials, vol. 25, no. 37, pp. 5321-5328, 2013.

[5] H.-M. Xiong, D. G. Shchukin, H. Möhwald, Y. Xu, and Y.Y. Xia, "Sonochemical synthesis of highly luminescent zinc oxide nanoparticles doped with magnesium(II)," Angewandte Chemie-International Edition, vol. 48, no. 15, pp. 2727-2731, 2009.

[6] W. Bunjongpru, P. Panprom, S. Porntheeraphat et al., "UVenhanced photodetector with nanocrystalline- $\mathrm{TiO}_{2}$ thin film via CMOS compatible process," in Proceedings of the IEEE Nanotechnology Materials and Devices Conference (NMDC '11), pp. 364-367, IEEE, Jeju, South Korea, October 2011.

[7] J. Cao, J. Wang, B. Fang, X. Chang, M. Zheng, and H. Wang, "Microwave-assisted synthesis of flower-like $\mathrm{ZnO}$ nanosheet aggregates in a room-temperature ionic liquid," Chemistry Letters, vol. 33, no. 10, pp. 1332-1333, 2004.

[8] U. Manzoor and D. K. Kim, "Size control of ZnO nanostructures formed in different temperature zones by varying Ar flow rate with tunable optical properties," Physica E: Low-Dimensional Systems and Nanostructures, vol. 41, no. 3, pp. 500-505, 2009.

[9] W. Q. Peng, S. C. Qu, G. W. Cong, and Z. G. Wang, "Synthesis and temperature-dependent near-band-edge emission of chainlike Mg-doped $\mathrm{ZnO}$ nanoparticles," Applied Physics Letters, vol. 88, no. 10, Article ID 101902, 2006.

[10] U. Manzoor, M. Islam, L. Tabassam, and S. U. Rahman, "Quantum confinement effect in $\mathrm{ZnO}$ nanoparticles synthesized by co-precipitate method," Physica E: Low-Dimensional Systems and Nanostructures, vol. 41, no. 9, pp. 1669-1672, 2009.

[11] X. L. Zhang, K. S. Hui, and K. N. Hui, "High photo-responsivity $\mathrm{ZnO}$ UV detectors fabricated by RF reactive sputtering," Materials Research Bulletin, vol. 48, no. 2, pp. 305-309, 2013.

[12] Y. Jin, Y. Ren, M. Cao, and Z. Ye, "Doped colloidal ZnO nanocrystals," Journal of Nanomaterials, vol. 2012, Article ID 985326, 8 pages, 2012.

[13] E. Burstein, "Anomalous optical absorption limit in InSb," Physical Review, vol. 93, no. 3, pp. 632-633, 1954.

[14] F. K. Shan, B. I. Kim, G. X. Liu et al., "Blueshift of near band edge emission in $\mathrm{Mg}$ doped $\mathrm{ZnO}$ thin films and aging," Journal of Applied Physics, vol. 95, no. 9, pp. 4772-4776, 2004.

[15] D. L. Golić, G. Branković, M. P. Nešić et al., "Structural characterization of self-assembled $\mathrm{ZnO}$ nanoparticles obtained by the sol-gel method from $\mathrm{Zn}\left(\mathrm{CH}_{3} \mathrm{COO}\right)_{2} .2 \mathrm{H}_{2} \mathrm{O}$," Nanotechnology, vol. 22, no. 39, Article ID 395603, 2011.

[16] G. H. Ning, X.-P. Zhao, and J. Li, "Structure and optical properties of $\mathrm{Mg}_{x} \mathrm{Zn}_{1-x} \mathrm{O}$ nanoparticles prepared by sol-gel method," Optical Materials, vol. 27, pp. 1-5, 2004.
[17] R. Wahab, S. G. Ansari, Y. S. Kim et al., "Low temperature solution synthesis and characterization of $\mathrm{ZnO}$ nano-flowers," Materials Research Bulletin, vol. 42, no. 9, pp. 1640-1648, 2007.

[18] A. Ohtomo, K. Tamura, M. Kawasaki et al., "Room-temperature stimulated emission of excitons in $\mathrm{ZnO} /(\mathrm{Mg}, \mathrm{Zn}) \mathrm{O}$ superlattices," Applied Physics Letters, vol. 77, no. 14, pp. 2204-2206, 2000.

[19] H.-C. Hsu, C.-Y. Wu, H.-M. Cheng, and W.-F. Hsieh, "Band gap engineering and stimulated emission of $\mathrm{ZnMgO}$ nanowires," Applied Physics Letters, vol. 89, Article ID 013101, 2006.

[20] U. Manzoor and D. K. Kim, "Synthesis and enhancement of ultraviolet emission by post-thermal treatment of unique zinc oxide comb-shaped dendritic nanostructures," Scripta Materialia, vol. 54, no. 5, pp. 807-811, 2006.

[21] K. ul Hasan, N. H. Alvi, J. Lu, O. Nur, and M. Willander, "Single nanowire-based UV photodetectors for fast switching," Nanoscale Research Letters, vol. 6, article 348, 2011.

[22] H. Kind, H. Yan, B. Messer, M. Law, and P. Yang, "Nanowire ultraviolet photodetectors and optical switches," Advanced Materials, vol. 14, no. 2, pp. 158-160, 2002.

[23] C. Soci, A. Zhang, B. Xiang et al., "ZnO nanowire UV photodetectors with high internal gain," Nano Letters, vol. 7, no. 4, pp. 1003-1009, 2007.

[24] M.-W. Chen, C.-Y. Chen, D.-H. Lien, Y. Ding, and J.-H. $\mathrm{He}$, "Photoconductive enhancement of single $\mathrm{ZnO}$ nanowire through localized Schottky effects," Optics Express, vol. 18, no. 14, pp. 14836-14841, 2010.

[25] R. Afrin, J. Khaliq, M. Islam, I. H. Gul, A. S. Bhatti, and U. Manzoor, "Synthesis of multiwalled carbon nanotube-based infrared radiation detector," Sensors and Actuators A: Physical, vol. 187, pp. 73-78, 2012.

[26] H. Liu, Z. Zhang, L. Hu et al., "New UV-A photodetector based on individual potassium niobate nanowires with high performance," Advanced Optical Materials, vol. 2, no. 8, pp. 771778, 2014.

[27] N. Naderi and M. R. Hashim, "Visible-blind ultraviolet photodetectors on porous silicon carbide substrates," Materials Research Bulletin, vol. 48, no. 6, pp. 2406-2408, 2013.

[28] X. Fang, L. Hu, K. Huo et al., "New ultraviolet photodetector based on individual $\mathrm{Nb}_{2} \mathrm{O}_{5}$ nanobelts," Advanced Functional Materials, vol. 21, no. 20, pp. 3907-3915, 2011.

[29] S. Y. Bae, C. W. Na, J. H. Kang, and J. Park, "Comparative structure and optical properties of Ga-, In-, and Sn-doped $\mathrm{ZnO}$ nanowires synthesized via thermal evaporation," The Journal of Physical Chemistry B, vol. 109, no. 7, pp. 2526-2531, 2005. 


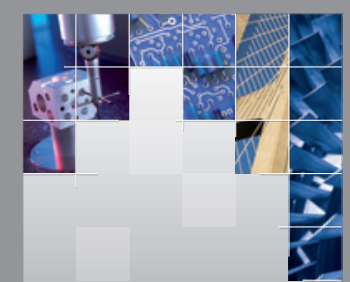

\section{Enfincering}
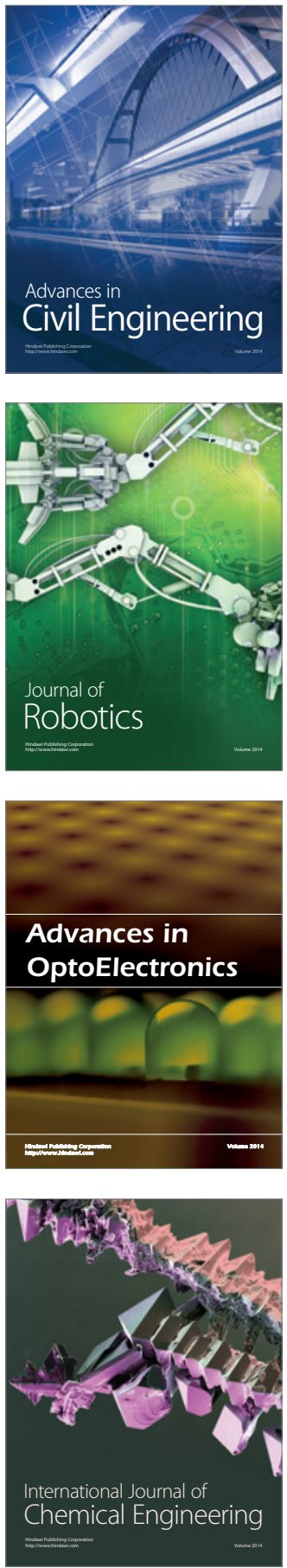

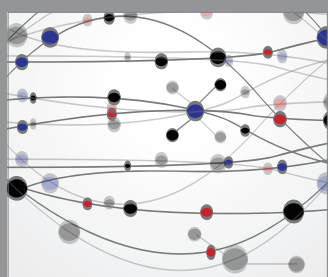

The Scientific World Journal

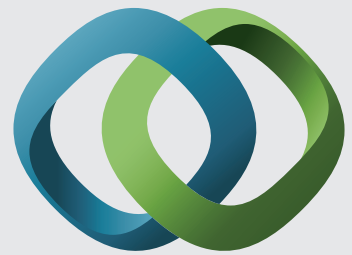

\section{Hindawi}

Submit your manuscripts at

http://www.hindawi.com
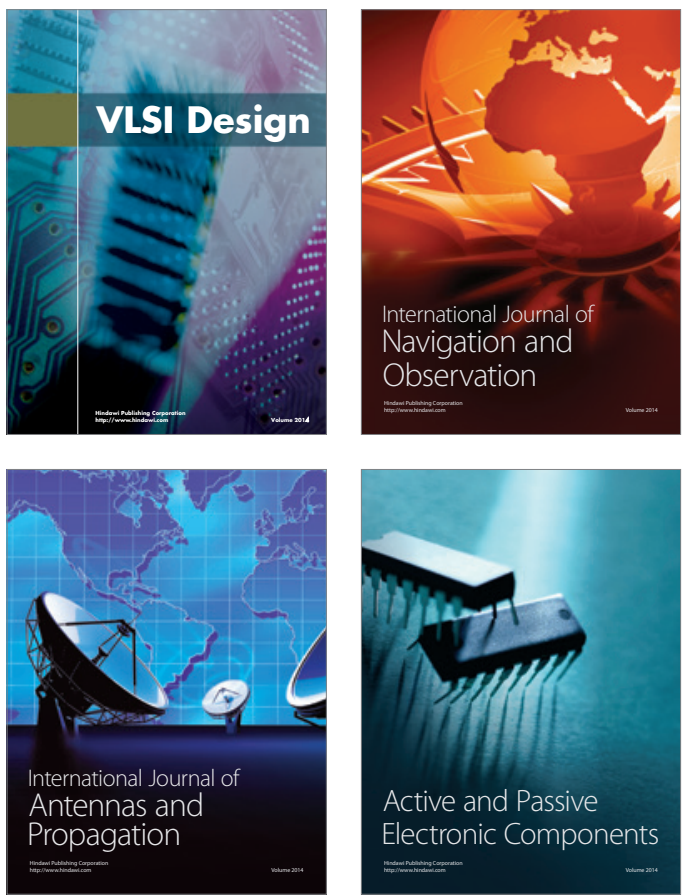
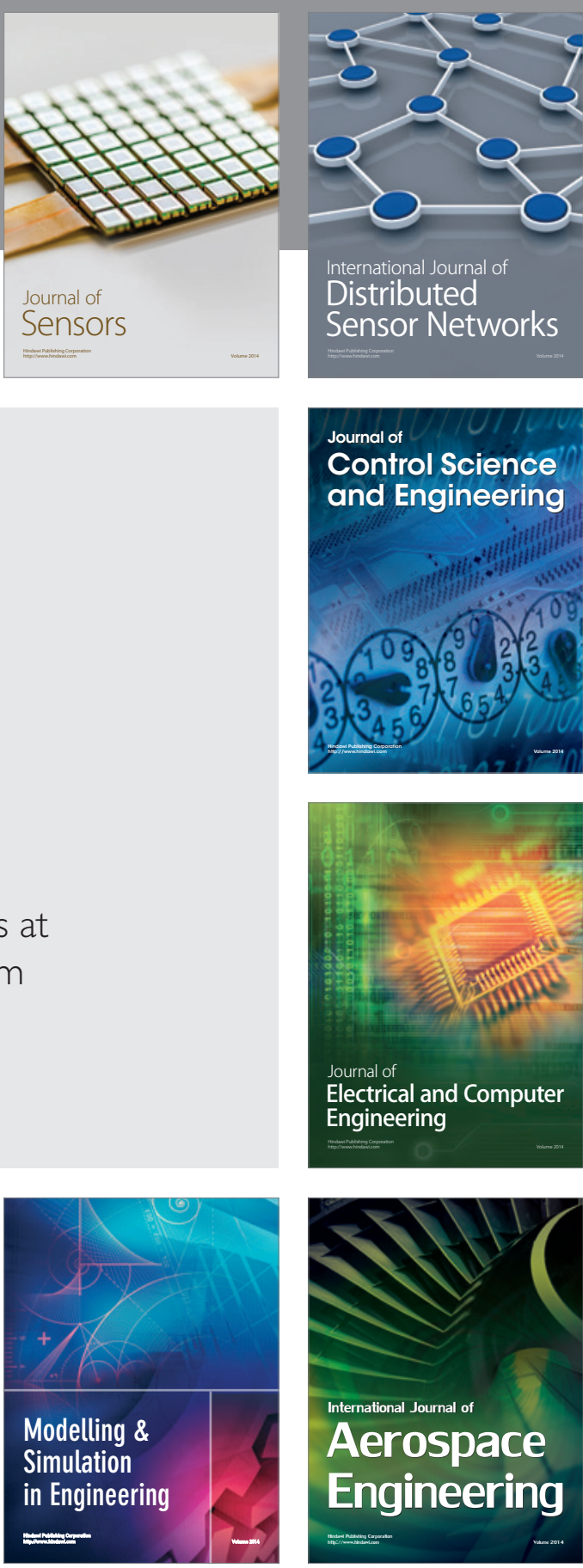

International Journal of

Distributed

Sensor Networks

Journal of

Control Science

and Engineering
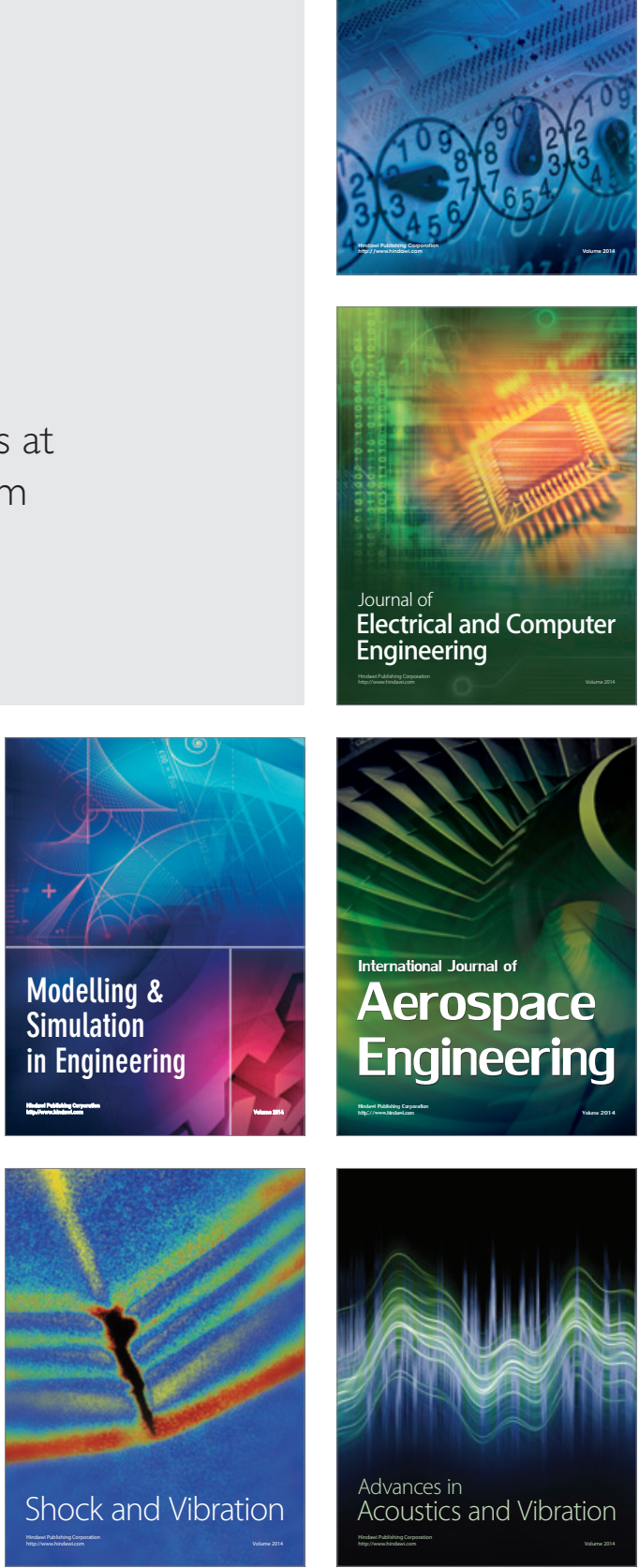